\title{
Feeling old in a young body: Women's experiences of living with severe consequences of an obstetric anal sphincter rupture: An interview study
}

\author{
Helen Elden ${ }^{* 1}$, Annica Olesen ${ }^{1}$, Linda Svahn ${ }^{1}$, Helena Lindgren ${ }^{1,2}$ \\ ${ }^{1}$ Institute of Health and Care Sciences, The Sahlgrenska Academy at University of Gothenburg, Sweden \\ ${ }^{2}$ Department of Women's and Children's Health, Karolinska Institute, Stockholm, Sweden
}

Received: June 27, 2014

DOI: $10.5430 /$ cns.v3n1p20
Accepted: October 26, $2014 \quad$ Online Published: November 5, 2014

URL: http://dx.doi.org/10.5430/cns.v3n1p20

\begin{abstract}
Background: The incidence of obstetric anal sphincter rupture (OASR) is increasing. It may cause anal incontinence and dyspareunia, leading to reduced quality of life and wellbeing. Qualitative studies are lacking. The aim was to describe experiences of living with ongoing severe consequences of an OASR $\geq 8$ weeks after childbirth.

Method: Twenty women with ongoing severe consequences of an OASR $\geq 8$ weeks after delivery were interviewed using qualitative content analysis.

Results: The experience of complications of an OASR is described in the overall theme "Feeling old in a young body" and four categories: The body as injured; isolation; inability to function sexually, and anxiety for the future. Participants described how the consequences of OASR totally occupied their lives, making them feel old in a young body. They told of repercussions for their physical, psychological, sexual and social lives; how it affected their roles of mothers and partners, making them fear future childbirths. Diet, use of medicines, coal filters in incontinence pads, timing of toilet visits, use of the environment and mobile phones to conceal flatus and/or feces were strategies participants described.

Conclusions: This study can contribute to increased understanding of how women can be affected by an OASR, and may enable healthcare personnel and authorities to meet their needs and organize care so that adequate support is available. It would also be beneficial if the women's physical strategies were integrated into the information provided by health caregivers involved in follow-up. However, more research in this area is warranted.
\end{abstract}

Key Words: Obstetric anal sphincter rupture, Quality of life, Qualitative content analysis, Strategies, Sexual function

\section{Introduction}

Obstetric anal sphincter rupture (OASR) is a serious complication of vaginal delivery. ${ }^{[1]}$ It is defined as a third or fourth degree injury of the perineum. A third degree injury involves partial or complete disruption of the anal sphinc- ter muscles, and a fourth degree injury is a third degree tear where even the rectal mucosa is involved. Risk factors for OASR are: maternal age (> 35 years),${ }^{[1,2]}$ primiparity, ${ }^{[1,3,4]}$ prolonged second stage of labor (i.e. $>2$ hours), ${ }^{[1,5]}$ oxytocin argumentation, instrumental delivery (both mid release vacuum extraction [VE] and outlet VE),${ }^{[1]} \mathrm{VE}$ without

\footnotetext{
*Correspondence: Helen Elden; Email: Helen.elden@gu.se; Address: Institute of Health and Care Sciences, The Sahlgrenska Academy at University of Gothenburg Box 457, 40530 Gothenburg, Sweden.
} 
episiotomy, ${ }^{[6]}$ and birth weight $>4,000$ grams. ${ }^{[1,5]}$ The risk of an OASR with a subsequent birth is $7.1 \% .^{[6]}$ The incidence of OASR has increased internationally during the last decennium and ranges from $0.5 \%-10 \% .{ }^{[6]}$ Percentages in Finland, Denmark, Norway and Sweden are $0.6 \%, 4.1 \%$, $4.03 \%$ and $4.2 \%$, respectively. ${ }^{[7]}$ Research suggests that some of the reported increased incidence may be explained by improved diagnosis. For example, a study showed that the use of anal endosonography for the examination of injuries to the perineum increased the reported incidence of OASR from $11 \%$ to $24.5 \% .^{[8]}$ Obstetric training for both midwives and physicians has been shown to result in a lower incidence of OASR. ${ }^{[9]}$

OASR can lead to anal incontinence, ${ }^{[1]}$ defined as an involuntary leakage of fluid, solid stool or flatus. ${ }^{[10]}$ Women also report dyspareunia, ${ }^{[10]}$ reduction in both quality of life and their sense of wellbeing ${ }^{[11]}$ and prolonged time from birth until resumed sexual intercourse. ${ }^{[12]}$ Studies show that OASR might have severe physical and physiological effects on women. ${ }^{[13-16]}$ They reported feeling upset, tired, angry, resigned, frustrated and a sense of loss. They felt abandoned and vulnerable during labor and birth, suturing and the postpartum period as a result of the actions of their health care providers. Some women said that fear of a recurrence of an OASR was a reason for avoiding new pregnancies. ${ }^{[16]} \mathrm{De}-$ spite the negative effects of OASR on women's daily lives few seek medical assistance. ${ }^{[15]}$

\section{Aim of the study}

The aim of this study was to describe women's experiences of living with ongoing severe difficulties of an OASR $\geq 8$ weeks after delivery.

\section{Methods}

This study was conducted between January 2012 and December 2013 in Gothenburg, Sweden.

\subsection{Qualitative method}

The methodological approach of the study was qualitative with individual interviews and qualitative content analysis applied in an inductive way. ${ }^{[17]}$ The qualitative method was deemed applicable for the interpretation of different levels/depths of a phenomenon. The aim is to provide a concise and broad description of the phenomenon, the outcome of the analysis being the concepts or categories describing the phenomenon. ${ }^{[17,18]}$

\subsection{Informants}

\subsubsection{Recruitment of informants}

Eligible women for this study were under the care of a physiotherapist specialized in pelvic floor dysfunction. Inclusion criteria were women with ongoing complications of an
OASR $\geq 8$ weeks after delivery, and fluency in Swedish. To select information rich subjects for in-depth interviews, women were selected through a purposive sampling. The physiotherapist gave the women verbal information about the study in person or by phone. If they were interested in participation in the study, they received written information directly or by mail. Twenty-two women who fulfilled the inclusion criteria were asked to participate. Two women declined for personal reasons. Thus, 20 women accepted and were contacted by two of the authors (AO or LS) by telephone to book an interview.

\subsubsection{Description of informants}

Nineteen women were Caucasian and one woman was of Indian ethnicity. Median age was 29 years (range 21-38 years). All were living with a partner. The mean number of children was 1.4 (range 1-3). Mean birth weight of the baby was 3,874 grams (standard deviation 622 grams, range 2,934-5,342 grams). The women had different levels of education, but all except one woman had a level higher than primary school. For further characteristics(see Table 1).

\subsection{Data collection}

Individual in-depth interviews were conducted during 2012. An open-ended question was used: "Please, tell me about your delivery". In order to encourage the women to delve deeper into their experiences interviewers posed questions and asked for clarification i.e.; tell me more and how did you feel? At the end of the interview they were asked to highlight any other aspects of their experience they had not yet defined. All participants were informed of the availability of counseling services; however, none chose to accept extra support. Interviews were performed 11 weeks to 8 years after delivery (mean 6 months) and took place in a hospital setting, at home or at the workplace depending on preference. All interviews were conducted by AO or LS and lasted 17 to 75 minutes (mean $=47$ minutes). They were audio recorded and transcribed verbatim. Research was carried out according to the guidelines of the Helsinki Declaration (World Medical Association, 2004). According to Swedish law governing ethical review of research involving human subjects, this study did not require ethical approval. Before the interviews, the participants were informed that their participation was voluntary and that they had the right to withdraw at any time without being required to give a reason. Written, informed consent was obtained from all the participants.

\subsection{Data analysis}

A qualitative content analysis was used in an inductive manner. ${ }^{[17]}$ Analysis was conducted with the aim of generating knowledge and enhancing understanding. Authors AO and LS reread the data several times to obtain a sense of the whole. Phrases or sentences, which reflected the woman's 
experience of having an OASR, were selected. The data were identified. The selected codes were sorted into subcatwas divided into units of meaning that were later condensed. The condensed unit of the meaning was abstracted and labeled with a code. However, codes were discussed between all authors and those relevant to the purpose of the study egories by moving them back and forth between the text and units of meaning. The subcategories were merged into main categories. Finally, one main theme emerged. ${ }^{[18]}$

Table 1: Characteristics of the participants at the time of the interviews

\begin{tabular}{|c|c|c|c|c|c|c|c|}
\hline Id & Age & $\begin{array}{l}\begin{array}{l}\text { Level of } \\
\text { education }\end{array} \\
\end{array}$ & OASR & Time since delivery & Parity & Mode of delivery & Problem \\
\hline 1 & 27 & Medium & OASR at delivery & 7 months & 1 & Spontaneous delivery & $\begin{array}{l}\text { Incontinence for wind and } \\
\text { sexual function }\end{array}$ \\
\hline 2 & 26 & High & $\begin{array}{l}\text { OASR at the } 2^{\text {nd }} \\
\text { delivery }\end{array}$ & 8 months & 2 & Spontaneous delivery & Sexual function \\
\hline 3 & 27 & High & OASR at delivery & 9 months & 1 & Spontaneous delivery & $\begin{array}{l}\text { Feeling of heaviness, sexual } \\
\text { function }\end{array}$ \\
\hline 4 & 21 & Low & OASR at delivery & 10 months & 1 & $\begin{array}{l}\text { Vaginal operative delivery } \\
\text { with VE }\end{array}$ & Feeling of heaviness \\
\hline 5 & 29 & Medium & OASR at delivery & 5 months & 1 & $\begin{array}{l}\text { Vaginal operative delivery } \\
\text { with VE }\end{array}$ & No symptoms \\
\hline 6 & 30 & High & $\begin{array}{l}\text { OASR at the } 2^{\text {nd }} \\
\text { delivery }\end{array}$ & 8 months & 2 & Spontaneous delivery & Sexual function \\
\hline 7 & 28 & High & OASR at delivery & 3 months & 1 & Spontaneous delivery & $\begin{array}{l}\text { Incontinence for wind and soft } \\
\text { stools, pain, sexual function }\end{array}$ \\
\hline 8 & 38 & High & $\begin{array}{l}\text { OASR at the } 2^{\text {nd }} \\
\text { delivery }\end{array}$ & 5 months & 2 & Spontaneous delivery & Incontinence for wind \\
\hline 9 & 34 & High & $\begin{array}{l}\text { OASR at the } 1^{\text {st }} \text { and } \\
\text { 2nd delivery }\end{array}$ & 2 months & 2 & $\begin{array}{l}\text { Spontaneous delivery at } \\
\text { the } 1^{\text {st }} \text { and } 2 \text { nd delivery }\end{array}$ & Incontinence for soft stools \\
\hline 10 & 28 & Medium & OASR at delivery & 3 months & 1 & Spontaneous delivery & $\begin{array}{l}\text { Incontinence for wind and } \\
\text { urine, pain, sexual function }\end{array}$ \\
\hline 11 & 34 & High & OASR at delivery & 4 years & 1 & Spontaneous delivery & $\begin{array}{l}\text { Incontinence for wind and soft } \\
\text { stools, sexual function }\end{array}$ \\
\hline 12 & 32 & High & OASR at delivery & 5 months & 1 & Spontaneous delivery & Sexual function \\
\hline 13 & 36 & High & $\begin{array}{l}\text { OASR at the } 2^{\text {nd }} \\
\text { delivery }\end{array}$ & 5 months & 2 & $\begin{array}{l}\text { Vaginal operative delivery } \\
\text { with VE }\end{array}$ & $\begin{array}{l}\text { Sexual function, urinary } \\
\text { incontinence }\end{array}$ \\
\hline 14 & 26 & Medium & OASR at delivery & 2 years & 1 & Spontaneous delivery & $\begin{array}{l}\text { Incontinence for wind and soft } \\
\text { stools, sexual life }\end{array}$ \\
\hline 15 & 32 & Medium & OASR at delivery & 4 months & 1 & Spontaneous delivery & $\begin{array}{l}\text { Incontinence for wind and soft } \\
\text { stools }\end{array}$ \\
\hline 16 & 32 & High & $\begin{array}{l}\text { OASR at the } 1^{\text {st }} \\
\text { delivery }\end{array}$ & 6 years & 3 & Spontaneous delivery & $\begin{array}{l}\text { Incontinence for wind and soft } \\
\text { stools }\end{array}$ \\
\hline 17 & 27 & Medium & OASR at delivery & 5 months & 1 & $\begin{array}{l}\text { Vaginal operative delivery } \\
\text { with VE }\end{array}$ & Sexual function \\
\hline 18 & 30 & Medium & OASR at delivery & 3 years & 1 & $\begin{array}{l}\text { Vaginal operative delivery } \\
\text { with VE }\end{array}$ & $\begin{array}{l}\text { Incontinence for wind and soft } \\
\text { stools }\end{array}$ \\
\hline 19 & 37 & High & $\begin{array}{l}\text { OASR at the } 1^{\text {st }} \\
\text { delivery }\end{array}$ & 8 years & 2 & $\begin{array}{l}\text { Vaginal operative delivery } \\
\text { with VE }\end{array}$ & $\begin{array}{l}\text { Incontinence for wind and soft } \\
\text { stools }\end{array}$ \\
\hline 20 & 34 & High & $\begin{array}{l}\text { OASR at the } 2^{\text {nd }} \\
\text { delivery }\end{array}$ & 3 months & 2 & $\begin{array}{l}\text { Vaginal operative delivery } \\
\text { with VE }\end{array}$ & $\begin{array}{l}\text { Incontinence for wind and soft } \\
\text { stools }\end{array}$ \\
\hline
\end{tabular}

Level of education: High = University; Medium = College/upper high school, Low = Primary school, Parity = number of deliveries, VE = Vacuum Extraction

\section{Results}

Twenty women with severe consequences of an OASR $\geq$ 12 weeks (mean 6 months, range 2 months- 8 years) after delivery were interviewed. Five women who had continuing complications from their injury more than 2 years ago felt that they had learned to live with the consequences, and one woman no longer had symptoms (see Table 1). A theme
"Feeling old in a young body" and four categories emerged from the analysis describing the women's experiences of severe consequences of an OASR: 1) the body as injured, 2) isolation, 3) inability to function sexually and, 3) anxiety about the future, (see Table 2). Quotes illustrating the five categories are presented below. The women's names have been encoded. 
Table 2: Categorical system describing women's experiences of living with severe consequences of an OASR

\begin{tabular}{lll}
\hline Sub-categories & Categories & Theme \\
\hline $\begin{array}{l}\text { 1. Inability to control basic bodily functions } \\
\text { 2. Constant anxiety }\end{array}$ & The body as injured & \\
$\begin{array}{l}\text { 3. The need to conceal leakage } \\
\text { 4. Strategies for managing leakage }\end{array}$ & \\
$\begin{array}{l}\text { 1. Having no one to talk to } \\
\text { 2. Experiencing life as limited }\end{array}$ & Isolation \\
$\begin{array}{l}\text { 1. Reduced interest in intimacy } \\
\text { 2. Feeling unattractive }\end{array}$ & Inability to function sexually \\
$\begin{array}{l}\text { 1. Long term repercussions } \\
\text { 2. Fearing future births }\end{array}$ & Anxiety about the future \\
\hline OASR= Obstetric Anal Sphincter Rupture. &
\end{tabular}

\subsection{The body as injured}

\subsubsection{Inability to control basic bodily functions}

The women expressed frustration at not being able to control their basic bodily functions. They lived with constant fear of the leakage of urine, gas, faces and the ensuing smells, which inevitably led to a sense of embarrassment. The need to first prevent, and then quickly detect, fluid leakage was always present, and meant that it was impossible to relax in social situations. It was difficult to follow a conversation when your prime focus was being prepared to deal with leakage. One woman used the following words: "You are always a bit nervous, when it comes to passing gas, sometimes you just relax and then everything comes at once, so you can never relax, you always have to be prepared, hold your muscles tight and be vigilant, so it's always there disturbing everything." (Informant 18)

Women told how they used tampons vaginally at the gym, because it felt as if it also caused the rectal muscles to contract, which prevented leakage of feces and fluid. One woman said: "Sometimes it (the tampon) feels as if it prevents urine leakage, so you have to find your small tips and tricks." (Informant 16)

\subsubsection{Constant anxiety}

Constant anxiety meant that the women felt they were forced to involve their friends and family. They needed to be able to check if there was any apparent odor. One woman said: "I have sort of passed gas without really realizing it, and it was terribly embarrassing and very troubling." (Informant 7)

The women described how they never really felt clean or fresh: How it was not enough with paper after using the toilet. In order to feel clean it was necessary to use soap or other products. Repeated washing led to irritation and redness of the genital area as one woman said: "I then felt that my skin also became very irritated when I constantly washed and dried it, and using so much cleansing cream." (Informant 16)

Published by Sciedu Press

\subsubsection{The need to conceal leakage}

Some women felt their daily focus was on concealment of leakage. They used different strategies. One woman used menstrual pads with coal filters, which decreased odor. Another woman avoided rising from a sitting position until there was some kind of noise in the environment to block the sound of flatulence. A third strategy was a pause in activity at times when there was a threat of leakage, this women said: "You have to think ahead all the time, for example, I always have a wallet or cell phone or something in my pocket, and if I feel gas or faeces on the way I stop and pretend to be busy with the telephone or wallet so I can concentrate." (Informant 11)

The need for being constantly aware and prepared to react resulted in tension and a loss of energy for some women. One woman meant that fear from the lack of ability to prevent or control leakages in social situations forced her to plan her day. She said: "It requires an incredible amount of planning. Everything must be planned, constantly, whatever you do. If I am going to a party or something, I have to know what's on the menu, making sure I have everything with me, and consider how I feel today. I always have different sizes of protection with me, depending on leakage; this is something I cannot let go of." (Informant 11)

\subsubsection{Strategies for managing leakage}

The women told of developing strategies for managing leakage and avoiding embarrassing situations. They were forced to constantly plan ahead, which was new since their injury. The women felt they could no longer trust that aspect of their body. One woman said: "There isn't a day that passes that I don't think that if I'm going somewhere... I must think about going to the toilet before we leave the house..."(Informant 20)

For some women it was important to always be in close proximity of a toilet, especially if the place was unknown to them. This provided an opportunity to prevent leakage by making it to the toilet in time. One of them said: "I think 
about this every day, I am terrified of not making it to the toilet in time." (Informant 20)

Awareness and knowledge concerning the effects of diet on the digestive system was important. Coffee in the morning was seen as a way of facilitating a bowel movement in the hope this would increase the chances of the day going well. Certain foods were excluded from the diet, e.g. vegetables, which were a restriction that many women considered annoying. Medicines, for restricting flatulence, and other aids were employed as a way of preventing leakage, e.g. tampons, anal plugs and medicines. One woman said: "I go to work with my handbag filled with plugs, pads, Imodium and other stuff; I don't leave home without having everything with me." (Informant 11)

Many used pelvic floor exercises to try and regain muscle strength and prevent a future OASR. Some considered that despite training their pelvic floor muscles the flaccid vaginal musculature was unlikely to improve with age. Other women hoped that the more they trained the more their musculature would improve. One woman said: "It's just to keep training so that it will be all right again." (Informant 11)

\subsection{Feeling of loneliness with the injury}

\subsubsection{Having no one to talk to}

The women described a feeling of loneliness with their injury, often not knowing anyone with the same problem. Some had never heard about OASR resulting from childbirth. It was embarrassing having to communicate about a problem of such intimate nature to family and friends. It was not always certain that the women's partners or other close friends and family were understanding or sympathetic. The women felt that this was often due to their lack of knowledge of the problem.

"I knew no one who had experienced the same thing who could confirm my feelings. I can imagine that if you have diabetes or eczema or whatever, you can talk with people in the same situation and share your feelings with them, and that there are other people with the same problem." (Informant 16)

There was a tendency for the women to joke about their problems with leakage in order to find a way to relate their daily reality. Feelings of shame dictated whom the women shared their feelings with. Some women felt they could talk about their injury with family and friends while others said they chose only to talk to a selected few. One woman said: "I have no desire to talk openly about my delivery with just anyone. I have only been able to talk to my mother and partner." (Informant 4)

\subsubsection{Experiencing life as limited}

The women's daily lives were affected physically and emotionally, and their injuries resulted in lost self-confidence.
This had repercussions for their roles as mothers, partners and views of themselves as individuals. One woman expressed this as: "Even if the leakage is less, and it was in the beginning, it still affects one's self-confidence. You feel incomplete as a woman. I'm 30 years old, nothing is as before, so self-confidence is poor." (Informant 15)

The women were forced to plan activities according to how their stomachs functioned. This had repercussions for their social lives and psychological wellbeing. The fear of leakage caused the women to give up many activities; e.g. swimming with the children. Some of the women had been athletic before their injury but their inability to exercise muscle control led to a loss of will. Forfeiting activities led to feelings of defeat and loss. One woman said: "There are times when I choose not to go out or visit a friend because my stomach is bad and I never know when I am going to fart. You know, it doesn't help if there's no sound because it smells so bad, and you don't want to be sitting with others, so, whatever, I am a bit tired anyway, so I choose to stay home.” (Informant 18)

\subsection{Inability to function sexually}

\subsubsection{Reduced interest in intimacy}

Some of the women told how OASR affected their sex lives. They expressed fear that intercourse could be painful, and anxiety that the healed tear could rupture. It was a risk they were not prepared to take. It was difficult to relax and enjoy themselves as before and it resulted in a reduced interest in intimacy. One woman said: "I can have some sort of pleasure. But if we're at it a while... I become hesitant. I would rather not have sex because I know it's going to hurt." (Informant 17)

There were also concerns about leakage of feces during intercourse, which gave rise to feelings of shame. Sexual interest decreased and many of the women had not resumed regular sexual activity. One woman said: "I am not as interested in sex as I was before; no, I am not at all as interested. You never know if there is going to be, like, some sort of surprise." (Informant 1)

\subsubsection{Feeling unattractive}

Some of the women felt unattractive, and this had repercussions on their self confidence and physical contact with their partners. One woman said: "You have no self-confidence; you don't feel sexy and good looking anymore because you're not fresh. You feel worse than others; you feel worse because others aren't like this." (Informant 14)

They felt the loss of self-confidence was due to the change in appearance of their genitals. The injury was not always fully healed and there could be areas of damaged tissue. The women signaled that they were not interested in more than hugging those days they had a lot of leakage. However, 
physical intimacy with their partner was important. One woman told us: "You know, I have it (sex) for my partner's sake not for my own. It feels like a sacrifice having sex, and that feels really sad." (Informant 17)

Some of the women felt that it took longer after childbirth than they had hoped to resume what they considered a normal sex life. They felt they had no control over the circumstances, which led to the injury and subsequently affected their ability for sexually intimacy. Pain during and after intercourse and a sensation of heaviness in the perineum resulted in an overall reduction of sexual interest. One woman said: "I get really tense and it hurts, and it's no use to continue." (Informant 11) Some of the women expressed feelings of shame and guilt due to the reduction in sex life and its effects on their partner. One of them said: "I tried to have sex but it really, really hurt. I nearly cried and said it's not going to work, but I really wanted it to work." (Informant 17)

\subsection{Anxiety about the future}

\subsubsection{Long-term repercussions}

The women expressed a need for answers as to whether they would fully recover from their injury. They worried about a future affected by incontinence and were terrified that there would be no relief. This was constantly on some of the women's minds. One woman expressed this as: "Even if it's a physical injury, it affects your thoughts." (Informant 11) Even the immediate future with return to work after maternity leave was a cause for concern. The women saying their complaints had improved were happy, but they were worried about increasing problems in the future. One of them said: "Will I have future harm from it? So if I train it may be better now, but will I have greater problems when I'm? It's something I think about." (Informant 8)

\subsubsection{Fearing future births}

Some of the women felt that the idea of a new pregnancy and birth was frightening due to fear of sustaining the same injury, but even that their present symptoms could worsen. Those that wished for more children were considering alternative choices of childbirth. One woman expressed fear of a natural birth, she said: "No, I don't dare to. The pregnancy will be as usual but I do not want to give birth (vaginally)." (Informant 15)

The women described interpreting their choices as being between not having any more children, adoption, caesarean section, or vaginal birth. Some expressed their reluctance to even consider having more children; however the wish for siblings to their children was a motivating factor. One woman said: "The psychological effect on the next birth is significant. I was not scared of giving birth before, but I can say that I am now.” (Informant 7)

Published by Sciedu Press
To have more children was so important for some women that they did not allow themselves to consider that their complaints could get worse during a future pregnancy and childbirth. They expressed that a new baby was worth the risk of an additional OASR. One of them said: "We will definitely have more children. I'd like to try usual childbirth again; it's not as if it's no, next time will be a caesarean section, but of course I'm frightened that it will be worse and I'll be incontinent afterwards." (Informant 5)

One of the women told how she decided to have an elective caesarian section for her second delivery because of fear for a new OASR. However, another woman told how she decided to have a vaginal childbirth the second time and had a new OASR, but that the difficult symptoms didn't last long after this delivery.

\section{Discussion}

The women's descriptions of living with ongoing consequences of an OASR resulted in the main theme: feeling old in a young body, and the categories: the body as injured; feelings of loneliness with the injury; inability to function sexually; and strategies for managing leakage and anxiety about the future.

\subsection{Study method}

This study presents data collected in a thorough manner, and the results provide an insight into the experiences of suffering from severe perineal trauma. Nevertheless, the results should be viewed in light of the context and the situations of the participants, and may, therefore, not be representative. There are methodological considerations to be taken into account when interpreting and transferring results derived through the use of a qualitative method, such as the influence of the researcher during the interview, as well as during the process of analysis. ${ }^{[18]}$ Interviewers were midwives, and their experience as care providers for women in the studied situation might have influenced the interviews. On the other hand, it is possible that the participants felt safe and shared more of their experience with someone who recognized the situation they described. The analysis was critically discussed and compared by all authors with the themes moving back and forth between the entire text and subcategories and categories to enhance credibility. ${ }^{[18]}$ Regarding trustworthiness, the findings can be useful for communicating the meaning of the studied subject. ${ }^{[19]}$ The issue of transferability is addressed in this study by the clear description of the data collection and analytical process. Additionally, results were in agreement with other studies confirming conformability. ${ }^{[20]}$ However, one must be humble toward transferability because there is always something else to see. The self-recruitment approach probably implies that participants are mostly women interested in the topic of the present study. 
The study had several limitations. The women in our study received comparatively good support and information due to quick and effective referral to a physiotherapist specialized in pelvic floor dysfunction. This appears to be particular for the area where the study was conducted. Another limitation is that some of the women in our study were nearly symptom free when the interviews were conducted, so their stories do not reflect the results since they talked about how it had been rather than how it was to live with the consequences of OASR in real time. It is likely that the time interval from the delivery to eight weeks after OASR excluded women with no symptoms. A longer interval from delivery to interview, e.g. six months postpartum, might have resulted in greater participant variation, and may have revealed another set of long-term consequences after OASR. A difference in the experiences of the phenomenon was that participants whose deliveries occurred several years ago had learned to cope with the consequences using several strategies as compared with women suffering from OASR 2-10 months before the interview.

\subsection{Discussion of the results}

The main finding of this study was women's ability to create physical strategies to conceal and prevent anal leakage. The theme "feeling old in a young body" illustrates that the consequences of OASR are far reaching, and can result in social, psychological and physical changes in women's lives, both short and long term. In condensing their stories, five categories, with no internal order of importance, emerged.

\subsubsection{The body as injured}

The women described the body as injured. They had constant anxiety because life with OASR always involved the need to conceal leakage. The women used coal filters in incontinence pads, surroundings and mobile phones to conceal flatus and/or feces. These strategies have not been, as we know, mentioned in other studies. However, anxiety and need to conceal leakage are confirmed by other postnatal qualitative studies with women that had faecal incontinence, urine incontinence, and/or dyspareunia as consequences of an OASR. ${ }^{[14,21]}$ These women described being forced into an everlasting fight over the inability to control leakage. ${ }^{[21]}$

The incidence of OASR has significantly increased over the last decades, and one reason may be changes in labor care routines. ${ }^{[7]}$ It is important to protect the perineum during the second stage of labor. A study in which twenty homebirth midwives were interviewed found that the midwives took precautions to minimize the risk for complications. Protection of the woman's perineum was seen as an act of awareness not limited to the actual pushing phase but starting earlier, along with communication between the midwife and the woman. ${ }^{[22]}$ More research concerning prevention of OASR is needed. Techniques such as the modified Ritgens maneuver need to be compared to other mindsets, such as hands off management and communication, during the critical moments when the infant's head is crowning.

\subsubsection{Strategies for managing leakage}

The majority of the participants had differing degrees of anal incontinence, which seemed to create complications when it came to social situations. This made planning and prevention necessary. The women described creating plans to cope with social situations such as diet control and use of medicines. They found themselves having to struggle to be like others, having to cope with unknown situations, which arose in their emotional, physical and social lives This is similar to a qualitative study of women $(n=10)$ affected by grade 3 OASR leading to urine incontinence and dyspareunia. $^{[23]}$ The women described creating strategies to cope with social situations. Diet control, medication, coal filters in incontinence pads, timing of visits to the toilet, and the use of surroundings and mobile phones in order to conceal flatus and/or faces were strategies described in detail. These strategies have not been, as we know, mentioned in other studies.

\subsubsection{Feeling of loneliness with the injury}

The women described experiencing life as limited, feelings of loneliness with their injury, and having no one to talk with about it. These findings are consistent with a recent meta-synthesis of four qualitative studies $(n=46){ }^{[13]}$ A study from Denmark, which included women $(n=9)$ with a postnatal faecal incontinence of at least 6 months described that the women were forced to develop coping strategies over time, and adopt a "new kind of normal" into their daily lives. ${ }^{[21]}$

\subsubsection{Inability to function sexually}

Our study revealed that women had a reduced interest in intimacy and expressed grief over the loss of a functional sex life with their partner. The women stated that their bodies had changed i.e. parts of the genitalia. They felt that the condition of the vaginal tissues was different after OASR causing them to wait longer before resuming intercourse. Pain and fear of sutures breaking open and the injury being exacerbated by intercourse was the initial cause of fear during the time following childbirth. Later on the women began to experience feelings of shame and discomfort associated with the leakage of faeces during intercourse, which mad them feel even more unattractive. The women described feelings of embarrassment and difficulties relaxing during sexual intercourse. Pain was also a problem, and despite variations in sexual positions pain free intercourse was difficult to achieve. Anxiety about resumption of an active sex life after OASR and its deleterious effect on sexual function have been described in earlier studies. ${ }^{[23-26]}$ Participants told of shame and guilt due to the reduction in sex life and its effects on their partner. Bearing in mind the anxiety and iso- 
lation which the women felt, it seems highly likely that partners also feel similar emotions, and therefore have the same needs for discussion, support, and information. Support to both the woman and her partner may protect the couple from further strains on their relationship during the neonatal and early childhood period, a period with a relatively high level of separations among parents. ${ }^{[27]}$

\subsubsection{Anxiety about the future}

The women expressed concern about long-term repercussions of the OASR, i.e. how a future birth would affect the problems, which they were already experiencing. They told of how they feared the next birth. It was terrifying to consider the possibility of a similar injury occurring. This is a relevant concern given that a repeated injury is known to occur in seven of 10 women with a subsequent delivery. ${ }^{[6]}$ An interesting finding in our study was that the women made a distinction between the experience of bearing a child and giving birth, being pregnant for 40 weeks was considered a positive experience while the thought of the actual birth was frightening.

Although some of the women in our study considered refraining from another pregnancy, the predominant feeling was one of finding another solution such as caesarean section. Another alternative which health care providers may not be aware of was the option of adoption. An earlier study has shown similar results ${ }^{[21]}$ but the women in that study did not mention adoption as an alternative. Instead, they expressed their greatest anxiety for giving birth to large babies. They expressed frustration due to lack of involvement in decisions about subsequent delivery. This concern was not raised in our study and may reflect differences in the decision-making processes and available options within different maternity units.

\section{Conclusion}

This study shows that OASR can have repercussions for women's physical, psychological and social life for a significant length of time. It has been able to uncover another aspect of the lasting effects of OASR; women's ability to create physical strategies in order to conceal and prevent anal leakage. This study can contribute to an increased understanding of how women can be affected by an OASR, and may enable healthcare personnel and authorities to meet these women's needs and provide them with adequate care and support. It would also be of great benefit if the women's physical strategies became integrated into the information given by health caregivers involved in follow-up. However, more research in this area is warranted. For example, studies of prevention and treatment of OASR and studies of how the women's partners experience living with a woman with on-going severe problems due to OASR and how they cope with it.

\section{Acknowledgements}

This study was supported by the Foundation of the Health and Medical care committee of the Region of Västra Götaland (Sweden), grant number: VGFOUFBD - 346061.

\section{Conflicts of Interest Disclosure}

The author declares that there is no conflict of interest statement.

\section{References}

[1] Dudding TC, Vaizey CJ, Kamm MA. Obstetric anal sphincter injury: incidence, risk factors, and management. Annals of surgery. 2008; 247(2): 224-237. PMid:18216527. http://dx.doi.org/1 $0.1097 /$ SLA . 0b013e318142cdf 4

[2] Jander C, Lyernäs S. Third and fourth degree perineal tears. Predicting factors on a referral hospital. Acta Obstet Gynecol Scand. 2001; 80(3): 229-234. PMid:11207488. http://dx.doi.org/10.1080 $/ j .1600-0412.2001 .080003229 . x$

[3] Samuelsson E, Ladfors L, Wennerholm UB, et al. Anal sphincter tears: prospective study of obstetric risk factors. BJOG: an international journal of obstetrics and gynaecology. 2000; 107(7): 926-931. http://dx.doi.org/10.1111/j.1471-052 8.2000.tb11093.x

[4] Samarasekera DN, Bekhit MT, Preston JP, et al. Risk factors for anal sphincter disruption during child birth. Langenbeck's archives of surgery/Deutsche Gesellschaft fur Chirurgie. 2009; 394(3): 535538. http://dx.doi.org/10.1007/s00423-008-0441-0

[5] Gottvall K, Allebeck P, Ekébus C. Risk factors for anal sphincter tear: the importance of maternal position at birth. BJOG: an international journal of obstetrics and gynaecology. 2007; 114(10): 12661272. http://dx.doi.org/10.1007/s00423-008-0441-0
[6] Jango H, Langhoff-Roos J, Rosthoj S, et al. Risk factors of recurrent anal sphincter ruptures: a population-based cohort study. BJOG: an international journal of obstetrics and gynaecology. 2012; 119(13): 1640-1647. http://dx.doi.org/10.1111/j.1471-0 $528.2012 .03486 . x$

[7] Laine K, Gissler M, Pirhonen J. Changing incidence of anal sphincter tears in four Nordic countries through the last decades. Eur $\mathbf{J}$ Obstet Gynecol Reprod Biol. 2009; 146(1): 71-75. http://dx.d oi.org/10.1016/j.ejogrb.2009.04.033

[8] Andrews V, Sultan AH, Thakar R, et al. Occult anal sphincter injuries-myth or reality? Bjog. 2006; 113(2): 195-200. http: //dx.doi.org/10.1111/j.1471-0528.2005.00799.x

[9] Laine K, Pirhonen T, Rolland R, et al. Decreasing the incidence of anal sphincter tears during delivery. European journal of obstetrics, gynecology, and reproductive biology. 2009; 146(1): 71-75. http://dx.doi.org/10.1016/j.ejogrb.2009.04.033

[10] Marsh F, Lynne R, Christine L, et al. Obstetric anal sphincter injury in the UK and its effect on bowel, bladder and sexual function. European journal of obstetrics, gynecology, and reproductive biology. 2011; 154(2): 223-227. http://dx.doi.org/10.1016/j. ejogr b. 2010.09 .006

[11] Samarasekera DN, Bekhit MT, Wright Y, et al. Speakman CT: Longterm anal continence and quality of life following postpartum anal 
sphincter injury. Colorectal disease: the official journal of the Association of Coloproctology of Great Britain and Ireland. 2008; 10(8): 793-799. http://dx.doi.org/10.1111/j.1463-1318. $2007.01445 . \mathrm{x}$

[12] Radestad I, Olsson A, Nissen E, et al. Tears in the vagina, perineum, sphincter ani, and rectum and first sexual intercourse after childbirth: a nationwide follow-up. Birth. 2008; 35(2): 98106. PMid:18507580. http://dx.doi.org/10.1111/j.1523-5 36X. 2008.00222. X

[13] Priddis H, Dahlen H, Schmied V. Women's experiences following severe perineal trauma: a meta-ethnographic synthesis. J Adv Nurs. 2013; 69(4): 748-759. http://dx.doi.org/10.1111/jan.121 00

[14] Priddis H, Schmied V, Dahlen H. Women's experiences following severe perineal trauma: a qualitative study. BMC women's health 2014; 14(1): 32. http://dx.doi.org/10.1186/1472-6874-1 4-32

[15] Wagenius J, Laurin J. Clinical symptoms after anal sphincter rupture: a retrospective study. Acta obstetricia et gynecologica Scandinavica. 2003; 82(3): 246-250. http://dx.doi.org/10.1034/j .1600-0412.2003.00088.x

[16] Kumar R, Ooi C, Nicoll A. Anal incontinence and quality of life following obstetric anal sphincter injury. Archives of gynecology and obstetrics. 2012; 285(3): 591-7. http://dx.doi.org/10.10 07/s00192-010-1134-0

[17] Elo S, Kyngas H. The qualitative content analysis process. J Adv Nurs. 2008; 62(1): 107-115. http://dx.doi.org/10.1111/j.1 365-2648.2007.04569. $x$

[18] Graneheim U, Lundman B. Qualitative content analysis in nursing research: Concepts, procedures and measures to achieve trustworthiness. Nurse Educ Today. 2004; 24: 105-112. PMid:14769454. http://dx.doi.org/10.1016/j.nedt.2003.10.001
[19] Polit D, Beck C. Nursing Research, Generating and Assessing Evidence fo Nursing Practice (8th ed.) 2008.

[20] Paley J. Error and objectivity: cognitive illusions and qualitative research. Nursing philosophy: an international journal for healthcare professionals. 2005; 6(3): 196-209.

[21] Lind Rasmussen J, Ringsberg K. Being involved in an everlasting fight - a life with postnatal faecal incontinence. A quality study. Scand J Caring Sci. 2010(24): 108-114. PMid:19824947. http: //dx.doi.org/10.1111/j.1471-6712.2009.00693.x

[22] Lindgren HE, Brink A, Klinberg-Allvin M. Fear causes tears - perineal injuries in home birth settings. A Swedish interview study. BMC pregnancy and childbirth. 2011; 11: 6. PMid:21244665. http://dx .doi .org/10.1186/1471-2393-11-6

[23] Williams A, Lavender T, Richmond DH, et al. Women's experiences after a third-degree obstetric anal sphincter tear: a qualitative study. Birth. 2005; 32(2): 129-136. http://dx.doi.org/10.1111/j.0 730-7659.2005.00356.x

[24] Olsson A, Lundqvist M, Faxelid E, et al. Women's thoughts about sexual life after childbirth: focus group discussions with women after childbirth. Scand J Caring Sci. 2005; 19(4): 381-387. http: //dx.doi.org/10.1111/j.1471-6712.2005.00357.x

[25] Boij C, Matthiesen L, Krantz M, et al. Sexual function and wellbeing after obstetric anal sphincter injury. British journal of midwifery. 2007; 15(11): 684-688.

[26] Mous M, Muller SA, de Leeuw JW. Long-term effects of anal sphincter rupture during vaginal delivery: faecal incontinence and sexual complaints. BJOG: an international journal of obstetrics and gynaecology. 2008; 115(2): 234-238. http://dx.doi.org/10. $1111 / \mathrm{j} .1471-0528.2007 .01502 . \mathrm{x}$

[27] Hansson M, Ahlborg T. Quality of the intimate and sexual relationship in first-time parents - a longitudinal study. Sex Reprod Health care: official journal of the Swedish Association of Midwives. 2012; 3(1): 21-29. 